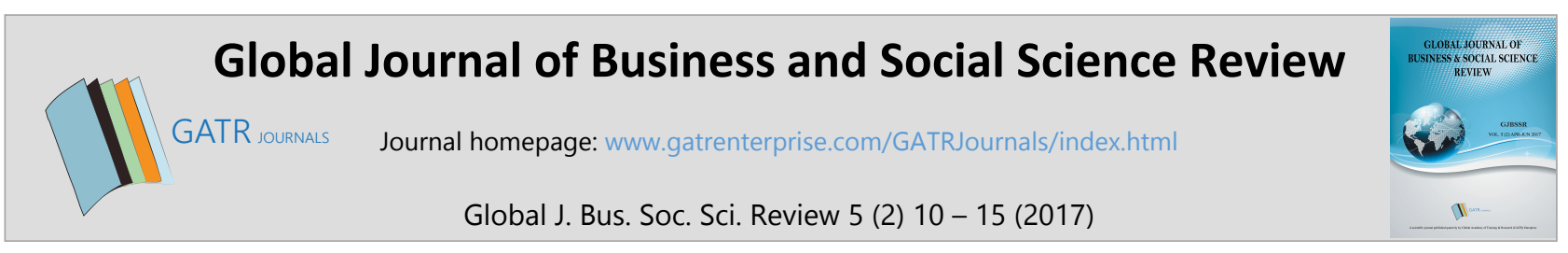

\title{
The Relationship between Contemporary Holacratic Models of Management and Company Performance: Evidence from Global Corporations in the World
}

\author{
Emil Velinov ${ }^{1 *}$ and Igor Denisov ${ }^{2}$ \\ ${ }^{1}$ Riga International School of Economics and Business Administration, Meza 8, 1048, Riga, Latvia \\ 2 Plekhanov Russian University of Economics, Stremianyi perlok. 36, 115093, Moscow, Russia
}

\begin{abstract}
Objective - This paper explores how global corporations apply contemporary approaches in management known as holacracy, and its impact on company performance. The paper argues that the number of corporations with an incorporated model of holacracy is growing and that it leads to an increase of employee's creativity and engagement, which directly affect a companys' performance. Furthermore, the study sheds light on broadening the theoretical link between holacratic management models and company performance in the context of global corporations at the level of internationalization. Methodology/Technique - The study provides evidence from over fifty selected worldwide companies for the period between 2014 and 2016. The data has been collected from annual reports and other secondary based sources and consists of companies possessing features of holacracy, which is one of the phenomena of management in the twenty-first century. In this paper, empirical data has been operationalized and several OLS regression models have been employed, in order to discover the link between modern management models and firm performance.

Findings - The paper's findings outline the fact that holacracy positively affects a companies' performance and that the number of global companies using holacratic models is growing.

Novelty - The study suggests that holacratic management models are connected to company success and performance through breakthrough innovative approaches in the context of employee communication and employee satisfaction, as a step-by-step approach that allows organizations to change gradually.
\end{abstract}

Type of Paper: Empirical.

Keywords: Holacratic Management Model; Corporations; Organizational Design. JEL Classification: M15, M54.

\section{Introduction}

For the last five to six years, there has been an increasing number of studies conducted which have explored and investigated different management models and practices across a variety of global companies from a variety of industries and business domains. At the same time, many studies have shifted their attention to contemporary management tools and approaches based on the soft features of the company including employee

\footnotetext{
* Paper Info: Revised: November 25, 2016

Accepted: April 21, 2017

* Corresponding author:

E-mail: emil.velinov@riseba.lv

Affiliation: Riga International School of Economics and Business Administration, Latvia
} 
engagement, mental models, channels of communications between top management teams and the rest of the management levels etc. Moreover, an incremental number of studies have researched contemporary management models such as McKinsey 7S model, Value-based Management Model, Sociocracy and Holacracy and many other modern approaches. However, very little attention has been paid to the relationship between management models and company performance, regardless of the universality of some management tools such as CRM, BCG matrix, Brainstorming and 360-degree feedback etc.

A flat organizational structure is defined as an organization with few levels (bands) or even just one level of management (Rishipal, 2012). This would mean the range of command is short, but the span of control is wide. Span of control is defined as the amount of people that are responsible for reporting to any of the managers. If the amount of employees reporting to one manager is large, then it is considered that the span of control is wide. If one manager has four employees reporting to them and another manager has eight, it is to be said that the second manager has a 'wider' span of control than the first manager. Therefore, Dr. Rishipal defines a flat structure as having a short chain of command, and a wide scope of control.

The main reason for writing this paper is to investigate how modern types of organizational structures, especially holacracy models, could have a positive affect on company performance in the management and business conditions of the twenty-first century. There are many challenges nowadays facing global organizations such as turbulent environments, short product life cycles, high employee fluctuations, generation-Z employees, employee satisfaction in the organization and many others, all of which represent significant barriers to the ability of companies to manage their businesses and sustain performance (McInnisDay, 2016). Additionally, global companies put a lot of effort into adapting their organizational structures to strategic planning methods and customer needs, which requires completely new and non-traditional approaches in implementing management practices and models. Organizations have slowly begun to realize that their management models should be more agile, flexible, feasible, adequate, fast-adapting and sustainable. This means that organizations should possess a suitable matrix of soft and hard features, which could enable them to sustain their business domains. We observe trends all over the world in the flattening of organizational structures, reducing hierarchy levels, merging roles and delegations among managers, decreasing the links between management levels but increasing interlocking among tier level management. The phenomenon of 'flat' organizations is taking place and in many business sectors there is an increasing trend of tall and flat organizational structures, aimed at reducing the hierarchy but retaining stable control over the company. Holacracy is one of the latest management approaches to emerge in terms of organizational structure and it is considered to be linked with the reinventing of organizations (Laloux and Wilber, 2014). Contemporary models of organizational structures are applied in both flat and tall organizations, regardless their size and industry segmentation.

\section{Literature Review}

Over five hundred companies across the globe are now using circular management in either its sociocratic or its holacratic version (Glass Frog, 2017). The majority of the companies included in the study sample are small or medium-sized. Companies such as the Dutch designer Fabrique, or the Brazilian agriculture company Terra Viva, are typical examples of holacratic management models using agile organizational structure consisting of circles. Each circle has several employees; one of them is the non-official leader of the circle, who represents this specific circle in the managerial hierarchy of the entire organization, along with the other circles. The informal leader of the circle is called the scrum master (see Figure 1). 


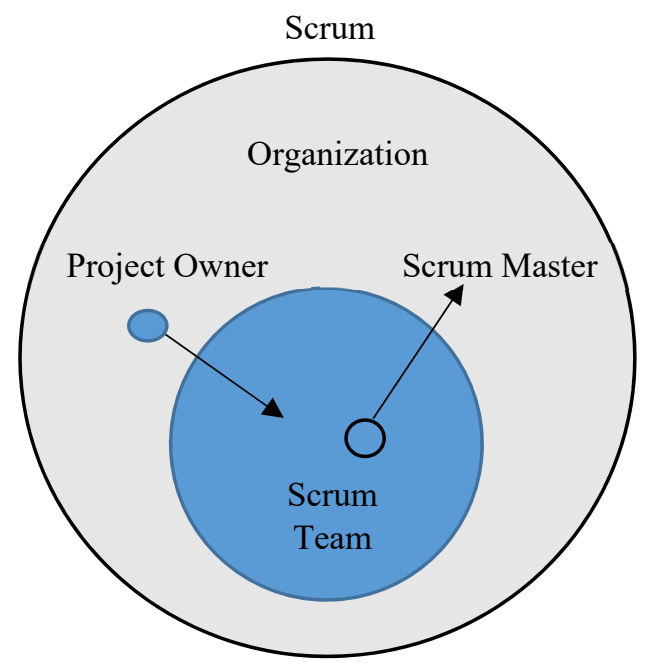

Figure 1: Scrum in Holacratic Management Model (2017)

There are interconnections among the circles in the organization based on informal communication and relationships among the employees (Gouveia, 2016). Large, publicly owned corporations are thus far not applying circular management - except for Zappos (shoe producer and division of Amazon) in which there is an ongoing effort to implement holacracy (Gelles, 2015). Only the sociocratic approach to circular management has been around long enough in order for organisations to assess its long-term impact; all organizations that use holacracy are leaders in their (local or regional) industries and, moreover, they have demonstrated how principles of circularity of power and authority enhance organizational resilience and performance as well as sustain empowerment at all levels of the organizational hierarchy (Romme, 2016; Romme and Endenburg, 2006). Furthermore, the management model of holacracy is based on the principles of self-managing organizations, where there is quite a lot of freedom in the approach to selection in decisionmaking procedures and all other management functions as long, as it brings about a positive result for the company.

In holacracy it is common to implement or request the replacement of hierarchies with a network of selfmanaged teams (Van de Kamp, 2014). While this may be working for some companies (with Zappos as probably the most prominent example), the fact is that most corporation (i.e. GE, Exxon Mobil, WalMart, et al.) have some sort of hierarchy, and changing this structure is not included in their strategic plans (Greenfield, 2015). However, these corporations are also steering their organizational structure toward a more agile structure. Thus, while flat organizations and holacracy might be desirable, they are often not within (quick) reach for a lot of enterprises.

\section{Research Methodology}

\subsection{Data Sample}

For the purpose of this paper, there is a list of 88 companies which are using either one or more features of holacracy in their management models. The data collection has been extracted from the website 'Structure and Process-Organizational Development' based on the company Glass Frog, which is expert on collecting data on holacracy as of $14^{\text {th }}$ of February 2017. Nowadays, it is very difficult to understand which companies are using holacratic management models if they do not disclose this information on their websites or in their annual reports. Therefore, the data set consists of only 88 out of a total of 526 companies from around the world that are officially known to use holacracy. 


\subsection{Statistical Operationalization and Hypotheses}

In this paper there are three hypotheses stated as follows:

According to John Kotter (2014) an organization should apply holacracy in order to increase their success and efficiency. Thus, employee performance and satisfaction are key factors for this success, which could be achieved by implementing flatter organizational structures such as holacracy. In this paper the first hypothesis is based on Kotter's study; that in general, having holacracy as a organizational structure is positively linked to higher company performance.

H1: Holacracy is positively related to company performance.

According to Romme and Endenburg (2006), small and medium-sized companies tend to be more suitable for implementing holacracy models in their organizational structure due to the fact that there is less hierarchy, less coordination is required and decision-making is faster. Therefore, in this study it is hypothesized that the smaller a company is, the more appropriate a holacratic management model will be.

$\mathrm{H} 2$ : The smaller the firm is, the higher the likelihood of success for a holacracy model.

In Table 1 below the descriptive statistics of the independent and dependent variables are provided:

Table 1: Descriptive Statistics

\begin{tabular}{|l|c|c|c|c|}
\hline Variable & Means & Std.Dev. & Min & Max \\
\hline Company age & 12 & 8.13 & 4 & 18 \\
\hline Company size & 77 & 34.41 & 5 & 150 \\
\hline Company Performance & 20 & 5.53 & 1 & 40 \\
\hline Company Internationalization & 23 & 4.10 & 1 & 45 \\
\hline Employees satisfaction & 16 & 5.92 & 11 & 22 \\
\hline Employees engagement & 12 & 0.41 & 7 & 17 \\
\hline $\mathrm{N}=88$, Cronbach $\alpha=0.61$ &
\end{tabular}

\section{Results and Discussions}

In this study, $\mathrm{H} 1$ was not supported and $\mathrm{H} 2$ was supported. The descriptive statistics illustrate that the statistical data was reliable as Cronbach $\alpha=0,61$. There was no connection found between the level of internationalization of the companies and their use of holacratic management models. Nevertheless, statistical data showed that companies with higher employee engagement and satisfaction are more likely to have entirely implemented holacracy models.

Interestingly, after the statistical operationalization was employed, we did not find any correlation between managerial practice/managerial holacratic model and company performance as there in neither evidence in the literature, which confirms this particular link.

\section{Conclusion}

The majority of the companies in the data set are small companies but the businesses tend to get bigger when scaling up, and as this occurs, those businesses are more often trying to implement management models consisting of self-organizing principles. This paper explains empirically that the principles of holacracy can provide a means for implementing self-organization at a larger scale - both within a single large project or product development efforts within an organization. In the software companies from the data sample there are currently many debates on new organization models such as teal organizations, flat organizations and flat 
archives etc. Doubtlessly, some of these models are promising, but they require complete restructuring of the company. Holacratic management models are connected to company success and performance through breakthrough innovative approaches in the context of employee communication and employee satisfaction, as a step-by-step approach that allows organizations to change gradually. Even though holacracy was established some 10 years ago, with the growing acceptance of software development and the emphasis on employee satisfaction, holacracy is becoming more and more accepted as an alternative management practice and a possible organization model. This means that much more research and practical experience is needed in order to explore the relationship between holacracy and company performance.

\section{References}

Gelles, D. (2015). At Zappos, pushing shoes and a vision. New York Times, 136.

Gouveia, L. B. (2016). Holacracy as an alternative to organisations governance. University Fernando Pessoa, Portugal. Greenfield, R. (2015). Zappos CEO Tony Hsieh: Adopt Holacracy or Leave. Fast Company.

Laloux, F. and Wilber, K. 2014. Reinventing Organizations: A Guide to Creating Organizations Inspired by the Next Stage of Human Consciousness. Nelson Parker.

Lemons, J. F. (2017). Issue: Flat Management Short Article: Consulting Firm Experiments with 'Holacracy'. California, SAGE Publishing.

McInnis-Day, B. (2016). Firms must adapt to a multi-generational workforce: international waters. HR Future, 2016(Nov 2016), 10-12.

Rishipal, D. (2012). Mangrial Effectiveness and Defense Mechunism Styles: A Comparison of Different Level of Managers .Iosr Journal of Business Management, 47-54.

Robertson, B. J. (2007). Organization at the leading edge: Introducing Holacracy ${ }^{\mathrm{TM}}$. Integral Leadership Review, 7(3), 113.

Robertson, B. J. (2015). Holacracy: The revolutionary management system that abolishes hierarchy. Penguin UK.

Robertson, B. J. (2006). Holacracy: A complete system for agile organizational governance and steering. Agile Project Management Executive Report, 7(7).

Romme, A.G.L. and Endenburg, G. (2006), "Construction principles and design rules in the case of circular design", Organization Science, 17(2), 287-297.

Simon, H.A. (1967), "The business school: a problem in organizational design”, Journal of Management Studies,. 4(1), 1-16.

Van De Kamp, P. (2014). Holacracy_A radical approach to organizational design. Elements of the Software Development Process-Influences on Project Success and Failure. University of Amsterdam, 13-26.

\section{Appendix}

Table 2. List of companies with holacratic management model

\begin{tabular}{|l|l|}
\hline Name of the company & Name of the company \\
\hline HolacracyOne & Three Coins \\
\hline iGi Partners & Trillium Awakening Operations Circle \\
\hline Structure \& Process (public governance records) & Washington's Strengthening Families Collective \\
\hline Evolving Organisation & Becoming Parents Program \\
\hline Zappos.com & BC3-Boulder Community \\
\hline Downtown Project & Precision Nutrition \\
\hline David Allen Company & Beratergruppe Neuwaldegg \\
\hline Undercurrent & Moveline \\
\hline Future Logic & ITX Wireless \\
\hline AdScale Laboratories & liv.it \\
\hline Wonderworks Consulting & Concept7 (case report) \\
\hline Springest & talkSpirit (case report) \\
\hline BoP Innovation Center & ARCA (blog post) \\
\hline
\end{tabular}




\begin{tabular}{|l|l|}
\hline Impact Hub Amsterdam & Netcentric (blog post) \\
\hline Impact Hub Vienna & Buddhist Geeks (note) \\
\hline Impact Hub Company & Washington Technology Solutions \\
\hline Waterschap de Dommel (in parts of the organisation) & OZ \\
\hline Streamit (in parts of the organisation) & Voys (links) \\
\hline Center for Human Emergence & cidpartners GmbH \\
\hline CHE Synnervate & Colman Knight Advisory (link) \\
\hline Kolibri & Scarabee Biocoop (report) \\
\hline The Integral Center & Energized.org \\
\hline Conscious Brands & soulbottles \\
\hline Outformations Agile Collaboratory & CourageLabs LLC \\
\hline Connectis & MankindProject USA \\
\hline Butterfly Works & Xpreneurs GmbH \\
\hline Rockstart & ACNV-BF \\
\hline Smart Hotel & Die Wertschätzer \\
\hline PRO6 Managers & Doctusoft \\
\hline Durabilis & FinanceFox \\
\hline VillageOffice & EMPAUA \\
\hline Paramount Software Solutions & SocialSquare (blogpost) \\
\hline LIIP - Agile Web Development & Findasense (video) \\
\hline Ticketfrog & AFCA \\
\hline MySign & CINTEO \\
\hline HolacracyOne (public governance records) & VSE \\
\hline iGi Partners & People's Playground \\
\hline Connectis & Lab.Coop (blogpost) \\
\hline Butterfly Works & bol.com (in some teams) \\
\hline Green-Acres & Spindle \\
\hline encode.org & Purely Poultry \\
\hline evolution at work & CompassPoint (blogpost) \\
\hline Business School Lausanne & Valsplat (post) \\
\hline Dwarfs\&Giants & Encode.org \\
\hline
\end{tabular}

Source: Structureprocess.com (2017) 